\title{
Evaluation of Factor VIII Polysialylation: Identification of a Longer-Acting Experimental Therapy in Mice and Monkeys ${ }^{[\mathrm{s}}$
}

\author{
Helmut Glantschnig, Alexander Bauer, Karima Benamara, Michael Dockal, Veronika Ehrlich, \\ Herbert Gritsch, Gerald Höbarth, Frank M. Horling, Alexandra Kopic, Peter Leidenmühler, \\ Birgit M. Reipert, Hanspeter Rottensteiner, Tanja Ruthsatz, Gerald Schrenk, Maria Schuster, \\ Peter L. Turecek, Alfred Weber, Martin Wolfsegger, Friedrich Scheiflinger, \\ and Werner Höllriegl
}

Baxalta Innovations $\mathrm{GmbH}$, a Member of the Takeda Group of Companies, Vienna, Austria

Received May 21, 2019; accepted July 8, 2019

\begin{abstract}
Extended half-life (EHL) factor therapies are needed to reduce the burden of prophylaxis and improve treatment adherence in patients with hemophilia. BAX 826 is a novel polysialylated fulllength recombinant factor VIII [polysialyic acid (PSA) rFVIII] with improved pharmacokinetics (PK), prolonged pharmacology, and maintained safety attributes to enable longer-acting rFVIII therapy. In factor VIII (FVIII)-deficient hemophilic mice, PSArFVIII showed a substantially higher mean residence time $(>2$-fold) and exposure ( $>3$-fold), and prolonged efficacy in tail-bleeding experiments (48 vs. 30 hours) compared with unmodified recombinant FVIII (rFVIII), as well as a potentially favorable immunogenicity profile. Reduced binding to a scavenger receptor (low-density lipoprotein receptor-related protein 1) and von Willebrand factor (VWF) as well as a largely VWFindependent circulation time in mice provide a rationale for prolonged BAX 826 activity. The significantly improved PK profile versus rFVIII was confirmed in cynomolgus monkeys
\end{abstract}

[mean residence time: 23.4 vs. 10.1 hours; exposure (area under the curve from time 0 to infinity): $206 \mathrm{vs} .48 .2 \mathrm{IU} / \mathrm{ml} \cdot \mathrm{h}$ ] and is in line with results from rodent studies. Finally, safety and toxicity evaluations did not indicate increased thrombogenic potential, and repeated administration of BAX 826 to monkeys and rats was well tolerated. The favorable profile and mechanism of this novel experimental therapeutic demonstrated all of the requirements for an EHL-rFVIII candidate, and thus BAX 826 was entered into clinical assessment for the treatment of hemophilia A.

\section{SIGNIFICANCE STATEMENT}

Prolongation of FVIII half-life aims to reduce the burden of prophylaxis and improve treatment outcomes in patients with hemophilia. This study shows that polysialylation of PSArFVIII resulted in prolongations of $r F V I I I$ circulation time and procoagulant activity, together with a favorable nonclinical safety profile of the experimental therapeutic.

\section{Introduction}

The major challenges in the management of hemophilia are prolonging the half-life and reducing the immunogenicity of recombinant clotting factors, and thus reducing the frequency of complications from repeated venous access, improving patient adherence to prophylactic regimens, and enhancing patient outcomes (Pipe, 2005; Peyvandi et al., 2013). Advances in factor-based treatment of hemophilia A include conjugating

This study was funded by Baxalta Innovations GmbH, a Member of the Takeda Group of Companies.

H.Gl., A.B., M.D., H.Gr., B.M.R., H.R, G.S., M.S., P.L.T., A.W., M.W., F.S., and W.H. are employees of Baxalta Innovations GmbH, a Member of the Takeda Group of Companies, Vienna, Austria. K.B., V.E., G.H., F.M.H., A.K., and T.R. were employees of Baxalta Innovations GmbH, a Member of the Takeda Group of Companies, at the time the current study was performed. The authors hold patents, stock, and/or stock options in Takeda Pharmaceutical Company Limited.

https://doi.org/10.1124/jpet.119.260067.

S This article has supplemental material available at jpet.aspetjournals.org. human recombinant factor VIII (rFVIII) to various entities in order to extend its half-life and circulation (Mahlangu et al., 2018). Linking B-domain deleted rFVIII to the Fc domain of human $\mathrm{IgG}_{1}$, for example, resulted in factor half-life extension (Dumont et al., 2012; Mahlangu et al., 2014), while chemically modifying factor VIII (FVIII) by polyethylene glycol (PEG) has been shown to decrease clearance from the circulation and extend FVIII half-life (Turecek et al., 2012; Tiede et al., 2013; Coyle et al., 2014; Konkle et al., 2015). Most modification techniques have achieved an overall maximum extended halflife (EHL) of FVIII of 1.5-1.8 times the baseline; however, this EHL remains modest compared with that reached with other therapeutics (Laffan, 2016; Balkaransingh and Young, 2018). It has been hypothesized that clearance of modified rFVIII variants is largely regulated by interaction with von Willebrand factor (VWF); therefore, this association is suggested to be a limiting factor (Pipe et al., 2016).

Modification with biodegradable polysialyic acid (PSA), a polymer of $\mathrm{N}$-acetylneuraminic acid, is a promising method

ABBREVIATIONS: EHL, extended half-life; FVIII, factor VIII; KO, knockout; LRP1, low-density lipoprotein receptor-related protein 1; MRT, mean residence time; PEG, polyethylene glycol; PK, pharmacokinetics; PSA, polysialyic acid; PSArFVIII, polysialyated recombinant human factor VIII; rFVIII, recombinant human factor VIII; rVWF, recombinant von Willebrand factor; VWF, von Willebrand factor. 
used to improve the pharmacokinetics (PK) of therapeutic proteins (Zhang et al., 2014), while maintaining their structural integrity and activity (Gregoriadis et al., 1993, 2005). PSAylation is thought to affect and reduce receptor-mediated clearance, and albeit not yet fully understood its mode of action probably involves cell surface receptors such as low-density lipoprotein receptor-related protein 1 (LRP1), heparan sulfate proteoglycans, and asialoglycoprotein receptors (Gregoriadis et al., 2000; Peyvandi et al., 2013). However, this technology's potential remains untapped in the development of EHL products to treat bleeding disorders. In particular, studies investigating the effects of PSAylation on PK and procoagulant activity of rFVIII have not been reported thus far.

We initiated a discovery program to assess the feasibility of using PSAylation to extend the half-life of drug products to treat bleeding disorders. Evaluation of PSAylation is based on the well-known safety and efficacy of recombinant full-length FVIII (Dhillon, 2012), and achieved by covalently coupling aminooxy-PSA to carbohydrate moieties to N-linked glycans. Human rFVIII is heavily glycosylated, with most N-linked glycans (19/25) and all seven O-linked glycans located in the B-domain, a domain that is dispensable for FVIII procoagulant activity (Toole et al., 1986). We comprehensively assessed the degree of full-length rFVIII PSAylation that is necessary and sufficient for optimized PK, efficacy, and immunogenicity attributes.

Here, we present the preclinical PK, pharmacology, and safety of this novel therapeutic approach, which led to identification of the clinical lead candidate BAX 826, the first PSAylated experimental therapeutic developed for the treatment of hemophilia [see clinical testing of BAX 826 (identifier: NCT02716194) at ClinicalTrials.gov].

\section{Materials and Methods}

\section{Materials}

The full-length rFVIII and polysialyated rFVIII (PSArFVIII) formulations used in the presented studies were based on ADVATE (Baxalta US Inc., a Member of the Takeda Group of Companies, Lexington, MA). rFVIII was conjugated with a diaminooxy-linker (3-oxa-pentane-1,5-dioxyamine) to polysyalic acid polymers $(20 \mathrm{kDa}$; Xenetic Biosciences, Inc., Lexington, MA) as previously described (Siekmann et al., 2014); the structure and chemistry are detailed in Fig. 1. The PSAylation process was controlled through various degrees of modification $(5.4,10.4,13.3$, and $16.4 \mathrm{~mol} \mathrm{PSA} / \mathrm{mol} \mathrm{rFVIII})$. The defined BAX 826 PSAylation degree approximates $10 \mathrm{~mol} / \mathrm{mol}$. As a control treatment and for factor dilutions, the following Trisbuffer was used: $10 \mathrm{mM}$ Tris, $1.7 \mathrm{mM} \mathrm{CaCl}_{2}, 3.2 \%$ (w/v) mannitol, $90 \mathrm{mM} \mathrm{NaCl}, 0.8 \%$ (w/v) $\alpha$-trehalose, $10 \mathrm{mM}$ histidine, $0.08 \mathrm{mg} / \mathrm{ml}$ glutathione (reduced), and $0.01 \%$ polysorbate- 80 ( $\mathrm{pH} \sim 7.0$ ). Human recombinant VWF (rVWF) was obtained from Baxalta US Inc. All treatments were administered by intravenous injection. The FVIIIdeficient mouse models are described in the Supplemental Material. All of studies complied with national laws governing animal experimentation and were approved by the respective animal care committees.

\section{In Vitro Evaluation of Human PSArFVIII Pharmacologic Activity}

Citrated rat, monkey, and human plasma was diluted with citrate buffer $[(1+2)$ rat and cynomolgus or $(1+1)$ human], resulting in reduced levels of coagulation factors, and then spiked with increasing

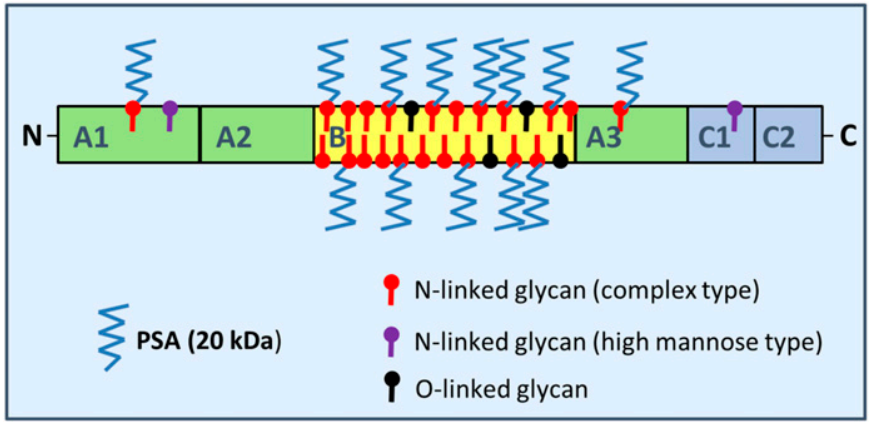

Fig. 1. Schematic presentation of PSA and rFVIII structures in PSArFVIII (BAX 826). The $20 \mathrm{kDa}$ PSA polymer is a linear homopolymer composed of $\mathrm{N}$-acetylneuraminic acid (2-keto-5-acetamido3,5-dideoxy-D-glycero-D-galacto-nonulo-pyranos-1-onic acid) monomers. Monomers in PSA used to manufacture BAX 826 are linked in an $\alpha-2,8$ manner. The chemistry for the PSAylation of rFVIII in BAX 826 makes use of free aldehyde groups generated by mild oxidation of sialic acids of $\mathrm{N}$-glycans of the protein with $\mathrm{NaIO}_{4}$. PSA containing an active aminooxy group was used to react with the free aldehyde groups of the protein. PSA is preferentially coupled to N-linked glycans (complex type) within the $\mathrm{B}$-domain of rFVIII. Indicated are also $\mathrm{N}$ - or O-linked glycans where PSAylation was not detected (Schrenk et al., 2016).

concentrations of PSArFVIII (0, 1, 5, and $10 \mathrm{U} / \mathrm{ml})$. Activated partial thrombin time was analyzed in duplicate with Pathromtin-SL (Siemens, Erlangen, Germany) using a KC4 coagulometer (Amelung GmbH, Lemgo, Germany).

\section{Determination of the Interaction of PSArFVIII with Low-Density Lipoprotein Receptor-Related Protein 1}

Interaction of PSArFVIII with LRP1 was determined using an ELISA combined with a chromogenic assay for FVIII activity. In brief, plasma-derived LRP1 (BioMac, Leipzig, Germany) was immobilized on a microtiter plate and dilutions were added of rFVIII or PSArFVIII. After incubation, unbound FVIII was removed by a washing step and FVIII bound to LRP1 was quantified using a chromogenic FVIII activity assay (Technochrom FVIII:C; Technoclone, Vienna, Austria).

\section{Determination of the Interaction of PSArFVIII with Von Willebrand Factor}

FVIII binding to plasma-derived VWF (Diagnostica Stago, Asnières sur Seine, France) immobilized on the flow cells of a CM5 biosensor chip at targeted densities of 300,600 , and 1200 response units was analyzed using Biacore T200 (GE-Healthcare, Uppsala, Sweden). Samples were diluted with running buffer [10 mM Hepes, $150 \mathrm{mM}$ $\mathrm{NaCl}$, and $0.05 \%$ Surfactant $\mathrm{P} 20$ ( $\mathrm{pH} \mathrm{7.4)]} \mathrm{in} \mathrm{five} \mathrm{dilutions} \mathrm{from}$ 0.18 to $5 \mathrm{nM}$ FVIII and applied to the chip (single-cycle mode; $50 \mu \mathrm{l} / \mathrm{min}$ constant flow rate). Association and dissociation times were 4 and 10 minutes, respectively. Binding was quantitatively determined by evaluating the calculated maximum binding at saturation $\left(R_{\max }\right)$.

\section{PK Studies in FVIII Knockout Mice}

Male and female hemophilic B6.129S4-F $8^{\text {tmKaz }}$ mice [FVIII knockout (KO) mice] (Bi et al., 1995) were used (body weight: 17-39 g). All stock formulations were diluted to final concentrations of $20 \mathrm{U} / \mathrm{ml}$ and administered via single intravenous bolus dose $(10 \mathrm{ml} / \mathrm{kg})$ at a nominal dose level of $200 \mathrm{U} / \mathrm{kg}$. Blood was collected from anesthetized mice ( $n=6 /$ time point/group) via cardiac puncture at 5 minutes, and $1,3,6,16,24,32$, and 40 hours. Plasma FVIII activity was measured and analyzed as described in the Supplemental Material. 


\section{Pharmacodynamic Studies in Mouse Models of Human Hemophilia A}

Efficacy Study (Tail-Bleeding Assay) Treating Acute Bleeds in FVIII KO Mice. FVIII KO mice were administered buffer or rFVIII or PSArFVIII of various PSAylation degrees at 10, 100, or $200 \mathrm{U} / \mathrm{kg}$ in the lateral tail vein 5 minutes before bleeds were induced by tail clip ( $N=16 /$ group; 8 male/8 female).

Efficacy Study (Tail-Bleeding Assay) in FVIII KO Mice with Prophylactic Treatment Mode. The prolongation of efficacy of rFVIII PSAylation was assessed in FVIII KO mice in the same tailbleeding model. Mice were administered buffer or $200 \mathrm{U} / \mathrm{kg} \mathrm{rFVIII}$ $(18,24,30$, or 40 hours) or BAX $826(24,30,40,48$, or 54 hours) before bleeding was induced by clipping tail tips. Blood loss was assessed gravimetrically (milligrams) over 60 minutes and adjusted for body weight (milligram per gram) as previously described (Schiviz et al., 2014).

Prophylactic Efficacy Study (Arterial-Thrombosis Assay) in FVIII KO Mice. The study methodology (Baumgartner et al., 2010) used to test the efficacy of PSArFVIII or rFVIII via thrombogenic activity is detailed in the Supplemental Material.

\section{Comparative Immunogenicity Studies in Murine FVIII KO Transgenic Mice}

PSArFVIII immunogenicity was assessed in a hemophilic mouse model with a knockout of the murine FVIII that expresses a liverdirected human F8 cDNA transgene (E17 FVIII-KO human F8 cDNA transgenic mice) (van Helden et al., 2011), and in a hemophilic mouse model that expresses the human MHC-class II protein HLA-DRB1*1501 on the background of a knockout of the murine MHC-class II complex [E17 FVIII-KO human MHC-class II (HLA DR15)] (Steinitz et al., 2012). Mice ( 5 males $/ 5$ females per group) were intravenously administered eight weekly doses of buffer or PSArFVIII (10.4 or $13.3 \mathrm{~mol} / \mathrm{mol})$, or rFVIII. The dose levels were selected based on the clinically relevant dose of the reference item rFVIII (50 IU/kg) approximating $200 \mathrm{ng} /$ mouse, and a 5-fold higher dose level (1000 ng/mouse). An irrelevant, highly immunogenic human rFVIII protein variant was used as a control (van Helden et al., 2011). Blood was sampled before the first dose by retro-orbital bleeds and 1 week after the last dose via cardiac puncture. Plasma samples were tested for anti-human rFVIII, and anti-human PSArFVIII binding antibodies and their incidences were measured as described in the Supplemental Material.

\section{Mechanistic PK Study in FVIII/VWF Double-KO Mice}

FVIII/VWF double-KO mice (body weight: 18-35 g) were used and randomly allocated to treatment groups dosed with BAX 826 (200 U/kg), rFVIII (200 U/kg), and without or with rVWF (3000 U/kg). Formulations were premixed with buffer or rVWF and administered via single intravenous bolus dose (10 ml/kg). Blood was collected at 5 minutes, and 1, 3, 5, or 7 hours (rFVIII group: 5 minutes, and 1 and 3 hours). Vials dedicated to plasma FVIII activity analysis were preloaded with $\mathrm{rVWF}(1 \mathrm{U} / \mathrm{ml})$ to stabilize FVIII proteins ex vivo. Plasma VWF and FVIII activity was measured and analyzed as described in the Supplemental Material.

\section{Comparative PK Study in Cynomolgus Monkey Administered Single Doses of BAX 826 or rFVIII}

Cynomolgus monkeys (3 males/3 females per group) were intravenously administered a nominal dose of $350 \mathrm{U} / \mathrm{kg}$ BAX 826 or rFVIII, or buffer, and blood samples were collected at 0 (predose), 5, and 30 minutes, and 2, 6, 12, 24, 48, 60, 72, 96, 108, and 120 hours. All plasma samples were analyzed in a FVIII chromogenic assay and PSA-FVIII modification-dependent activity assay as described in the Supplemental Material.

\section{Safety Pharmacology and Toxicity Assessment}

Assessment of thrombogenic potential in a rabbit venous stasis model (Wessler et al., 1959) and of repeated dose toxicity in rats and cynomolgus monkeys is described in the Supplemental Material.

\section{Statistical Evaluation}

All calculations were performed with $\mathrm{R}$ version 3 or higher (http:// www.R-project.org/) and SAS version 9.2 for Linux. The level of statistical significance was set to $5 \%$. All comparisons are considered to be exploratory; therefore, no adjustment for multiplicity was applied (Supplemental Material).

\section{Results}

Confirmation of PSArFVIII-Retained Procoagulant Activity In Vitro. Activated partial thromboplastin time (APTT) in native rat, cynomolgus monkey, or human plasma was experimentally prolonged by dilution with citrate buffer. Supplementation with PSArFVIII (10.4 mol PSA/mol FVIII) led to a dose-dependent reduction and normalization of clotting time in all species (Table 1).

Polysialylation of rFVIII Reduces Interaction with LRP1 and VWF. Binding of PSArFVIII to LRP1 was tested using an ELISA-based format (Fig. 2A). All rFVIII and PSArFVIII samples investigated showed concentration-dependent binding to LRP1; however, this was markedly reduced versus unmodified rFVIII, with increasing degrees of PSAylation that further reduced binding. Association between PSArFVIII and VWF is shown in Fig. 2B. All rFVIII and PSArFVIII samples investigated showed concentration-dependent binding to VWF. Binding of PSArFVIII to VWF was markedly reduced and correlated negatively with increasing PSA degree.

Effect of Polysialylation Degree on rFVIII PK in FVIII KO Mice. When administered as a single intravenous dose to FVIII KO mice, the $C_{\max }$ estimates were higher in dose groups that received PSArFVIII than in the rFVIII group (Table 2). Clearance was profoundly reduced for PSArFVIII (9.25-11.01 ml/h per kilogram vs. $34.41 \mathrm{ml} / \mathrm{h}$ per kilogram for rFVIII). Statistically superior estimates for the area under the curve from time 0 to infinity and the mean residence time (MRT) were detected in all PSArFVIII dose groups (Fig. 3). Estimates for terminal half-lives for PSArFVIII ranged from 5.14 to 7.38 hours and thus were up to 2.3-fold longer than for rFVIII. Group differences for terminal half-lives (vs. rFVIII group) were significant except for the PSArFVIII formulation with the lowest PSA degree $(5.4 \mathrm{~mol} / \mathrm{mol})$.

Effect of Polysialylation Degrees on Acute rFVIII Pharmacodynamics in FVIII KO Mice. We next assessed the potency of rFVIII formulations with different degrees of PSA in a tail-bleeding model. Tail bleeds were initiated

\section{TABLE 1}

PSArFVIII ( $10 \mathrm{~mol} / \mathrm{mol})$ is pharmacologically active and fully reverses activated partial thromboplastin time (APTT) prolongation in diluted rat, cynomolgus monkey, and human plasma

$n=2$, mean values.

\begin{tabular}{lccc}
\hline \multirow{2}{*}{ PSArFVIII } & \multicolumn{3}{c}{ Activated Partial Thromboplastin Time } \\
\cline { 2 - 4 } & Rat & Cynomolgus Monkey & Human \\
\hline \multirow{2}{*}{$I U / m l$} & $s$ & $s$ & $s$ \\
0 & 42.5 & 42.5 & 57.3 \\
1 & 34.2 & 34.2 & 48.9 \\
5 & 29.3 & 29.3 & 40.0 \\
10 & 26.2 & 26.2 & 34.1 \\
Undiluted native plasma & 29.2 & 29.2 & 33.9 \\
\hline
\end{tabular}


A

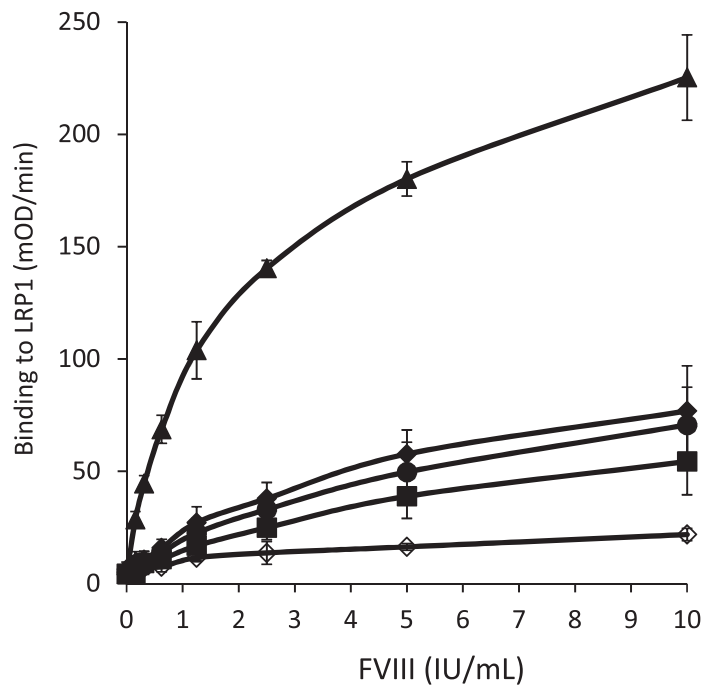

B

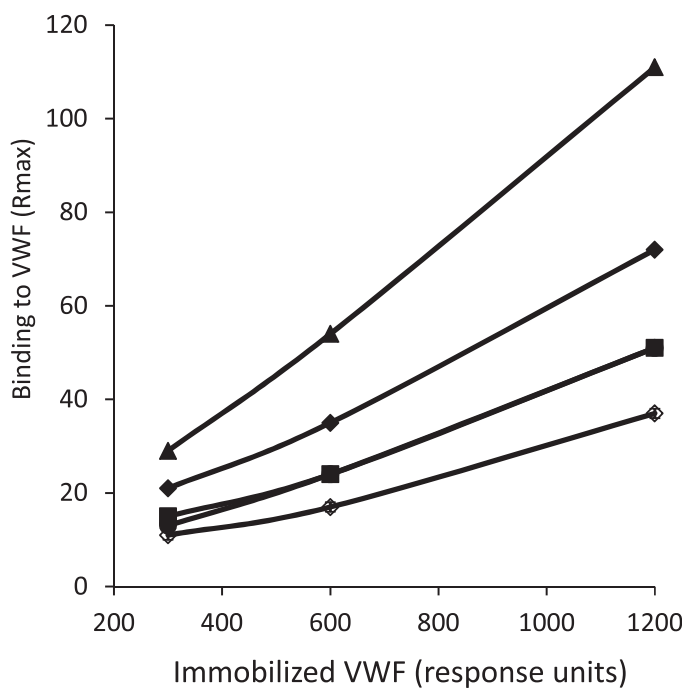

Fig. 2. In vitro evaluation of PSArFVIII interaction with LRP1 and VWF. (A) Binding to LRP1 was determined by an ELISA-combined chromogenic assay [mean \pm S.D., $N=3$; where the error bars whennot shown are too small to depict]. (B) Binding to VWF was determined by Biacore as the maximum binding at saturation ( $R_{\max }$; single measurements). rFVIII (triangles), PSArFVIII with a PSA degree (mol PSA/mol FVIII) of 5.4 (diamonds), 10.4 (circles), 13.3 (squares, dotted line), and 16.4 (open diamonds). Note that affinity of rFVIII to VWF ( $\left.K_{\mathrm{D}}: 0.19-0.25 \mathrm{nM}\right)$ was only slightly affected by polysialylation but similar for all PSA degrees $\left(K_{\mathrm{D}}: 0.39-0.41 \mathrm{nM}\right)$ as determined by Biacore (data not shown).

5 minutes after intravenous dosing to ensure testing at peak plasma concentrations in all dose groups (Fig. 4). The decrease in blood loss by treatment with rFVIII and PSArFVIII was dose related. Treatment with $\mathrm{rFVIII}$ was effective at all doses investigated and treatment with PSArFVIII was effective at the 100 and $200 \mathrm{U} / \mathrm{kg}$ doses (vs. buffer control group). However, no statistically significant difference (at the $5 \%$ level) in blood loss was observed between PSArFVIII- and rFVIII-treated groups at equivalent dose levels. Blood loss in PSArFVIII groups treated at the intermediate dose level (100 U/kg) showed larger within-group variability at higher PSAylation degrees (13.3 and $16.4 \mathrm{~mol} / \mathrm{mol}$ ) (Fig. 4). Thus, a relatively less robust pharmacologic effect might be inferred by the variable pharmacological activity at higher degrees of rFVIII-PSAylation. Guided by the PK and efficacy data in mice, formulations with PSAylation degrees of 10.4 and 13.3 were selected for further evaluation.

Comparative Immunogenicity Studies in Hemophilic Mouse Models. A FVIII KO mouse model was used to study the potential immunogenicity of the modified rFVIII, where
FVIII peptides are presented by HLA-DRB1*1501, as described previously (Steinitz et al., 2012). The incidences of mice evaluated as positive for anti-FVIII binding antibodies were $5 / 10$ and 7/9 mice treated weekly with rFVIII (200 or $1000 \mathrm{ng}$ ) after eight repeat doses (Table 3). At the same time point, the incidences of anti-FVIII antibodies in PSArFVIII groups $(10.4 \mathrm{~mol} / \mathrm{mol})$ were only $1 / 10$ and $2 / 10$, respectively, and the incidences in PSArFVIII groups $(13.3 \mathrm{~mol} / \mathrm{mol})$ were $4 / 9$ and $3 / 10$, respectively. The titer ranges were similar in all treatment groups.

To mimic the situation in previously FVIII-treated patients without inhibitors, human rFVIII-immunotolerant hemophilic mice were used, which develop antibodies against human FVIII only when immune tolerance breaks down (van Helden et al., 2011). Here, $4 / 10$ and 5/10 mice treated weekly with rFVIII (200 or $1000 \mathrm{ng}$ ) were evaluated as positive after eight repeat doses. The incidences of anti-FVIII antibodies in PSArFVIII groups $(10.4 \mathrm{~mol} / \mathrm{mol})$ were $0 / 10(200 \mathrm{ng} / \mathrm{wk})$ and $2 / 10$ (1000 ng/wk), and all mice in the PSArFVIII treatment groups $(13.3 \mathrm{~mol} / \mathrm{mol})$ were evaluated as negative for binding

TABLE 2

Summary of PK parameters after single-dose intravenous administration of PSArFVIII presentations or rFVIII to FVIII KO mice Values in parentheses refer to two-sided $95 \%$ confidence intervals; $n=6 /$ group/time point.

\begin{tabular}{|c|c|c|c|c|c|}
\hline \multirow{2}{*}{ Parameter } & \multicolumn{5}{|c|}{ rFVIII (200 IU/kg) } \\
\hline & PSAylation Degree: 5.4 & PSAylation Degree: 10.4 & PSAylation Degree: 13.3 & PSAylation Degree: 16.4 & PSAylation Degree: 0 \\
\hline & $\mathrm{mol} / \mathrm{mol}$ & $\mathrm{mol} / \mathrm{mol}$ & $\mathrm{mol} / \mathrm{mol}$ & $\mathrm{mol} / \mathrm{mol}$ & $\mathrm{mol} / \mathrm{mol}$ \\
\hline$C_{\max }(\mathrm{IU} / \mathrm{ml})$ & $4.33(3.89-4.76)$ & $2.92(1.83-4.01)$ & $3.70(2.90-4.51)$ & $4.22(3.82-4.63)$ & $2.40(1.14-3.66)$ \\
\hline IR (IU/ml)/(IU/kg) & $0.0143(0.0129-0.0158)$ & $0.0146(0.0092-0.0201)$ & $0.0176(0.0138-0.0214)$ & $0.0154(0.0139-0.0169)$ & $0.0101(0.0048-0.0154)$ \\
\hline Terminal half-life (h) & $7.37(1.54-13.20)$ & $6.51(5.19-7.82)$ & $5.14(4.65-5.63)$ & $7.38(6.55-8.20)$ & $3.20(2.71-3.70)$ \\
\hline $\mathrm{AUC}_{0-40 \mathrm{~h}}(\mathrm{IU} / \mathrm{ml} \cdot \mathrm{h})$ & $27.19(22.53-31.85)$ & $21.06(18.24-23.89)$ & $18.86(17.22-20.50)$ & $26.64(24.54-28.74)$ & $6.872(5.711-8.034)$ \\
\hline CL (ml/h per kilogram) & $10.93(9.21-12.64)$ & $9.34(8.1-10.6)$ & $11.11(10.14-12.09)$ & $10.05(9.23-10.88)$ & $34.7(26.83-40.57)$ \\
\hline$V_{\mathrm{dss}}(\mathrm{ml} / \mathrm{kg})$ & $97.96(78.22-117.7)$ & $84.65(71.94-97.36)$ & $80.12(73.08-87.15)$ & $102.7(93.20-112.3)$ & 144.9 (121.1-168.8) \\
\hline
\end{tabular}

$\mathrm{AUC}_{0-40 \mathrm{~h}}$, area under the curve from time 0 to $40 \mathrm{~h} ; \mathrm{AUC}_{0-\infty}$, area under the curve from time 0 to infinity; CL, clearance; $C_{\text {max }}$, peak plasma concentration; IR, incremental recovery; $T_{\max }$, time at $C_{\mathrm{max}} ; V_{\mathrm{dss}}$, volume of distribution at steady state. 

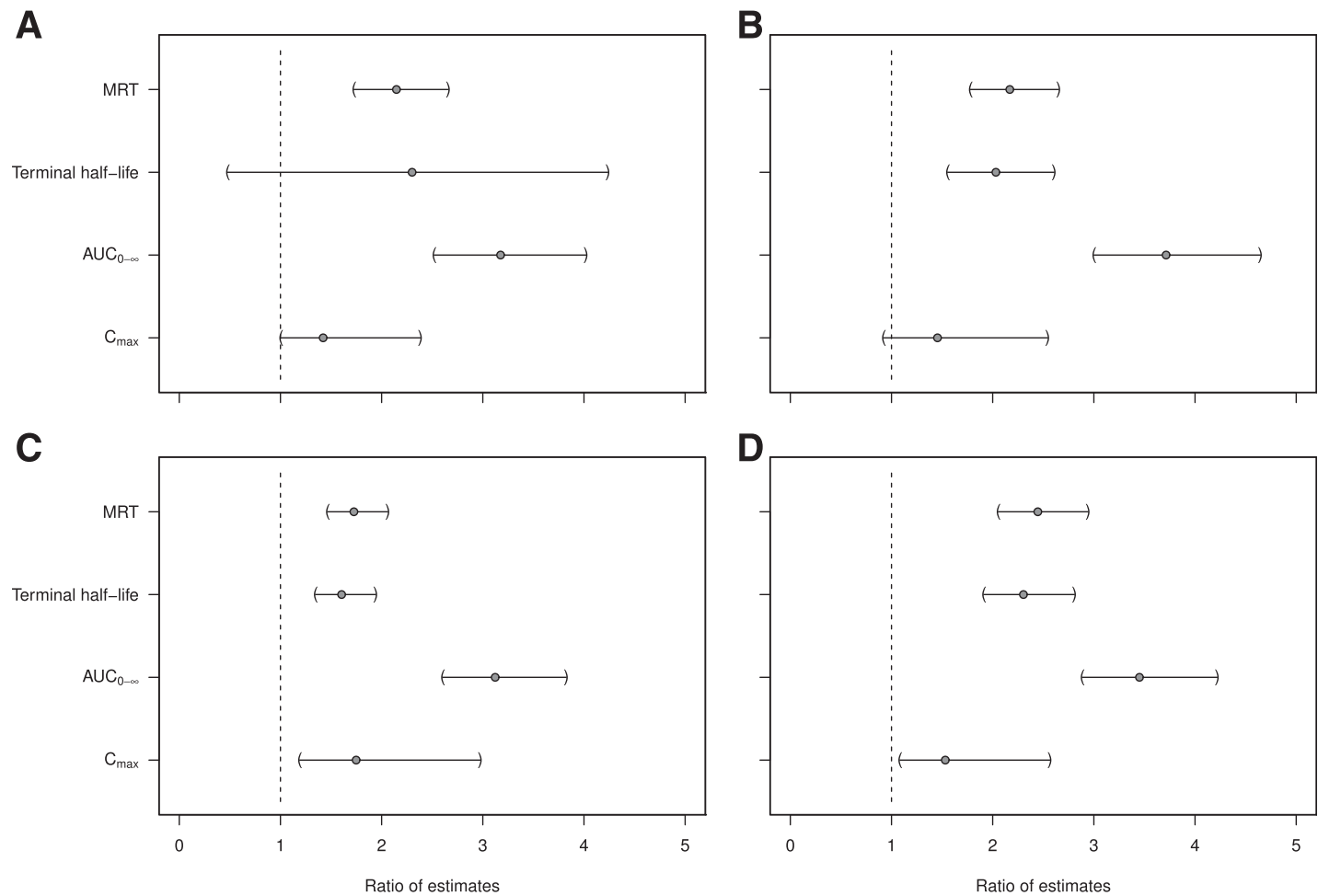

Fig. 3. Evaluation of PK parameters demonstrate improved circulation times and exposures by PSArFVIII preparations vs. rFVIII in FVIII KO mice. PK data were assessed using a serial sampling design where only one sample is taken per animal at one of the time points investigated. Unmodified rFVIII or PSArFVIII were administered intravenously $(n=6 /$ time point/group) at a dose of $200 \mathrm{IU} / \mathrm{kg}$. Shown are the group ratios between PSArFVIII [PSAylation degrees 5.4 (A), 10.4 (B), $13.3(\mathrm{C})$, and $16.4(\mathrm{D}) \mathrm{mol} / \mathrm{mol}$ ] and $\mathrm{rFVIII}$ and the corresponding two-sided 95\% confidence intervals (CIs) of the PK parameter maximum concentrations $\left(C_{\mathrm{max}}\right)$, area under curve from time zero to infinity $\left(\mathrm{AUC}_{0-\infty}\right)$, terminal half-life, and MRT. A two-sided $95 \% \mathrm{CI}$ for the ratio not containing the value of 1 , indicated by the vertical dashed line, is equivalent to rejecting the null hypothesis of no difference against the twosided alternative at the $5 \%$ level of statistical significance.

antibodies. The titer ranges were similar in all treatment groups (Table 3). In summary, no substantial differences in immunogenicity were observed between the two PSArFVIII formulations; therefore, the studies detailed subsequently focused on that with a relatively lower PSAylation degree of $10.4 \mathrm{~mol} / \mathrm{mol}$ (BAX 826).

Prolonged Efficacy of BAX 826 versus rFVIII in Prophylactic Treatment of Hemophilic Mice. We next tested the prophylactic use of BAX 826 assessing reductions in blood loss as well as for an extended period of effectiveness. Treatment was administered up to 54 hours before inducing bleeds in the tail-bleeding model. The median total blood loss in buffer-treated mice was $40 \mathrm{mg} / \mathrm{g}$ and was significantly reduced in rFVIII-treated groups when administered up to 30 hours before tail clip ( $22 \mathrm{mg} / \mathrm{g} ; P=0.0018$ ) (Fig. 5). BAX 826 was efficacious up to 48 hours $(20 \mathrm{mg} / \mathrm{g} ; P=0.0212)$, and while the effect size was largely diminished at the last time point tested (54 hours) group differences (vs. buffer) were still significant $(P=0.0377)$.

Prolonged Efficacy of BAX 826 in the Carotid Occlusion Model in FVIII KO Mice. Prolonged BAX 826 activity was further substantiated in a murine model of ferric chloride-induced arterial thrombosis (Baumgartner et al., 2010). Within the 30-minute observation period, no vessel occlusions were observed in buffer-treated animals. Pharmacologic activity by rFVIII and BAX 826 was demonstrated by a distinct decrease in time to occlusion (Supplemental Table 1). rFVIII was efficacious in groups treated up to 18 hours before denudation of the carotid endothelium (median time to occlusion 12.0 minutes; $P<0.001$ vs. buffer). Treatment with BAX 826 was efficacious in groups treated up to 30 hours before denudation (median time to occlusion 6.0 minutes; $P<0.001$ ).

Prolonged Circulation Time of BAX 826 Is Largely Independent of Interaction with VWF. To investigate the mechanistic basis for the prolonged efficacy, BAX $826 \mathrm{PK}$ was tested in FVIII/VWF double-KO mice in the absence or presence of coadministered human rVWF. Due to the deficiency of VWF, administered rFVIII is rapidly cleared from the circulation, and rFVIII activity was below the lower limit of quantification 3 hours after administration (Fig. 6A), with an estimated terminal half-life of 0.33 hours. Coadministration of rVWF improved the FVIII PK profile (Fig. 6A), and terminal half-life as expected (and significantly) reduced the clearance of rFVIII (Table 4). Although pharmacologic intervention with rVWF did not fully normalize rFVIII clearance to the levels seen in VWF-competent mice (see Table 2), terminal half-life and MRT were essentially comparable (Table 4). In stark contrast, BAX 826 was detectable in the absence of VWF at all time points (Fig. 6B) and terminal halflife was profoundly prolonged (5.5 hours), suggesting reduced clearance of BAX 826 in VWF-deficient mice similar to that seen in VWF-competent animals (see Table 2). Coadministration with $\mathrm{rVWF}$ resulted in modestly increased $C_{\max }$, and changes in terminal half-life and MRT were not statistically significant $(P \geq 0.767)$.

Comparative PK Studies in Cynomolgus Monkeys and Rats. To fully assess the potential of factor half-life extension by PSAylation, single doses of BAX 826, rFVIII, or buffer were administered in parallel. Activity was determined 


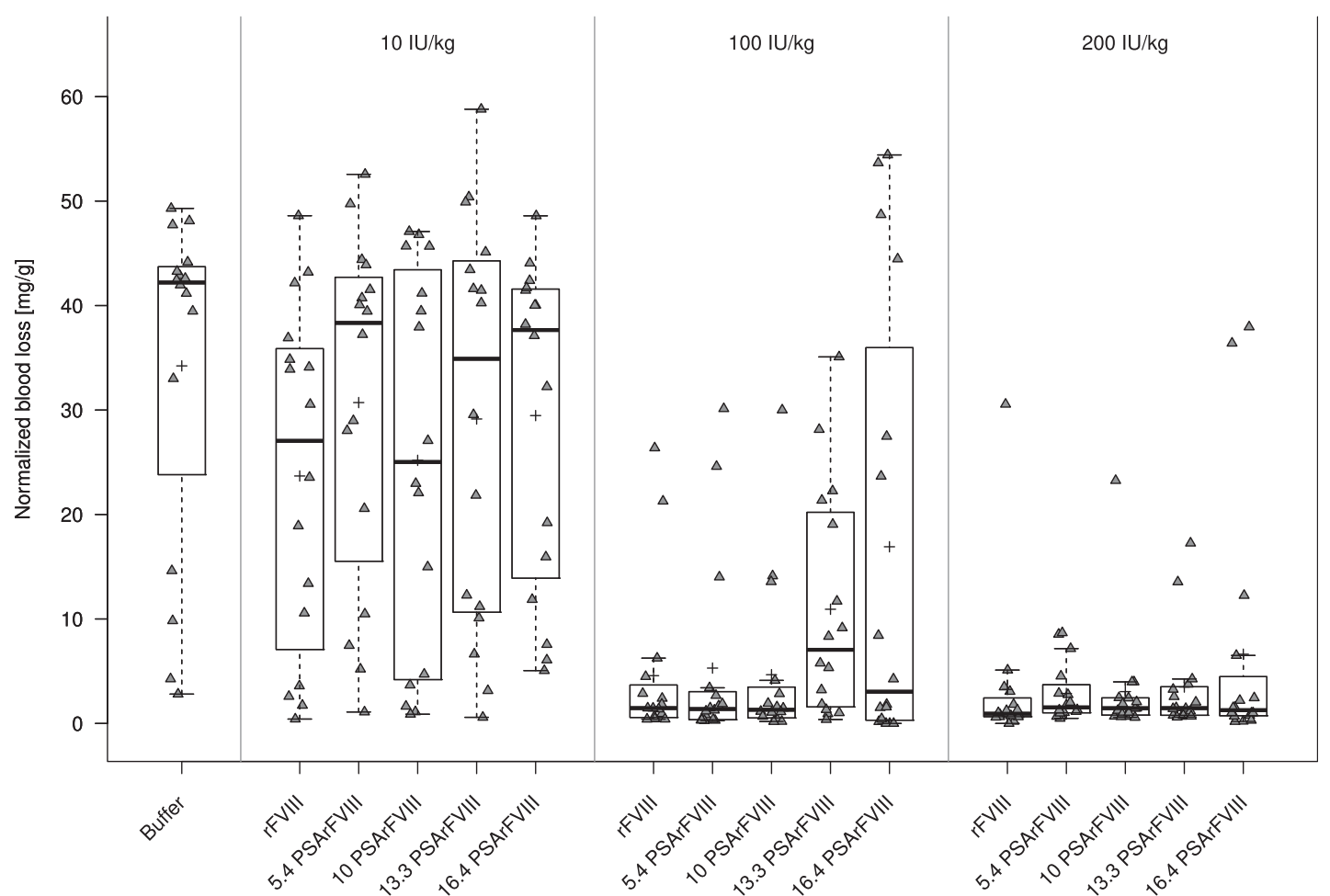

Fig. 4. Single-dose treatment with PSArFVIII (or rFVIII) shows dose-related procoagulant activity in hemophilic FVIII KO mice and robustness of pharmacological PSArFVIII activity affected by the degree of PSAylation. Buffer, unmodified rFVIII, or PSArFVIII (PSAylation degrees of 5.4, 10.4, 13.3 , and $16.4 \mathrm{~mol} / \mathrm{mol}$ ) were administered intravenously 5 minutes before bleeds were started. Treatment with rFVIII reduced median blood loss from $42.2 \mathrm{mg} / \mathrm{g}$ (control group) to $27.05 \mathrm{mg} / \mathrm{g}$ (10 U/kg), $1.47 \mathrm{mg} / \mathrm{g}$ (100 U/kg), and $0.93 \mathrm{mg} / \mathrm{g}$ (200 U/kg). Administration of increasing doses of PSArFVIII (with varying PSA degrees) reduced median blood loss ranging from 25.02 to 38.34 (10 U/kg), 1.31-7.05 (100 U/kg), and 1.27-1.53 (200 IU/kg). Body weight normalized blood loss over 60 minutes ( $n=16$ /group) is displayed using boxplots (see Supplemental Material).

in the presence of cynomolgus FVIII and corrected accordingly. Similar $C_{\max }$ values were determined after administration of BAX 826 or rFVIII (Table 5). However, reduced clearance (2.25 vs. $6.72 \mathrm{ml} / \mathrm{h}$ per kilogram), prolonged FVIII activity terminal halflife (18.5 vs. 8.0 hours), and MRT (23.4 vs. 10.1 hours), resulting in a substantial increase in exposure to FVIII activity (area under the curve from time 0 to infinity of 206 vs. $48.2 \mathrm{U} / \mathrm{ml}$ h), were recorded in the BAX 826-treated group. FVIII activity increased over baseline up to 48-72 hours in BAX 826-treated animals and up to 12-24 hours in the rFVIII-treated group (Fig. 7A). The ratios of geometric mean values (BAX 826/rFVIII) and corresponding two-sided $95 \%$ confidence intervals confirmed similar $C_{\max }$ values and significantly improved the area under the curve from time 0 to infinity, terminal half-life, and MRT (Fig. 7B).

To further and specifically assess BAX 826 activity in FVIIIcompetent cynomolgus monkeys, the same plasma samples were tested in a modification-dependent activity assay format (Table 5). Activity was detected in plasma from all treated animals and was above the lower limit of quantification $(0.05 \mathrm{U} / \mathrm{ml})$ up to 72-96 hours after dosing. Overall, the PK results using this assay format substantiated the characteristics for BAX 826 assessed previously. Additional comparative PKevaluations in rats further supported the extended circulation time observed for BAX 826 over rFVIII (Supplemental Table 2).

Evaluation of BAX 826 Thrombogenic Potential in a Rabbit Venous Stasis Model. Assessment of the thrombogenic potential (Wessler et al., 1959) at an exceedingly high dose level of BAX 826 (900 U/kg) showed no evidence of heightened thrombogenicity in individual scores (range $0-2$; mean 0.42 ) or compared with scores in the group treated with $900 \mathrm{U} / \mathrm{kg} \mathrm{rFVIII}$ (range 0-1; mean 0.67). The percentages of BAX 826- and rFVIIItreated animals without evidence of thrombi formation were

TABLE 3

Anti-FVIII antibody response in hemophilic mouse models

Incidence of plasma samples evaluated as positive for anti-FVIII antibodies after eight weekly administrations of buffer, PSArFVIII formulations, $r F V I I I$, or treatment with a positive control rFVIII protein in respective hemophilic mouse models. Titer ranges within each study group are indicated. As expected, no anti-FVIII antibodies were detected in buffer control-treated animals of either mouse model, whereas all (9/9) positive control-treated human FVIII-transgenic mice showed breaking of immune tolerance.

\begin{tabular}{|c|c|c|c|c|c|c|c|c|c|}
\hline \multirow{2}{*}{ Hemophlic Mouse Model } & \multirow{2}{*}{ Parameter } & \multirow{2}{*}{ Buffer } & \multicolumn{2}{|c|}{ PSArVIII $10.4 \mathrm{~mol} / \mathrm{mol}$} & \multicolumn{2}{|c|}{ PSArVIII $13.3 \mathrm{~mol} / \mathrm{mol}$} & \multicolumn{2}{|c|}{ rFVIII } & \multirow{2}{*}{ Control:1000 ng/wk } \\
\hline & & & $200 \mathrm{ng} / \mathrm{wk}$ & $1000 \mathrm{ng} / \mathrm{wk}$ & $200 \mathrm{ng} / \mathrm{wk}$ & $1000 \mathrm{ng} / \mathrm{wk}$ & $200 \mathrm{ng} / \mathrm{wk}$ & $1000 \mathrm{ng} / \mathrm{wk}$ & \\
\hline FVIII KO, HLA-DRB1*1501 Tg & Incidence & $0 / 10$ & $1 / 10$ & $2 / 10$ & $4 / 9$ & $3 / 10$ & $5 / 10$ & $7 / 9$ & ND \\
\hline E17 murine FVIII KO, human F8 Tg & Titer range & $0-0$ & $0-0$ & $3-11$ & $0-0$ & $1-1$ & $4-9$ & $1-9$ & $5-13$ \\
\hline
\end{tabular}

ND, not determined. 
A

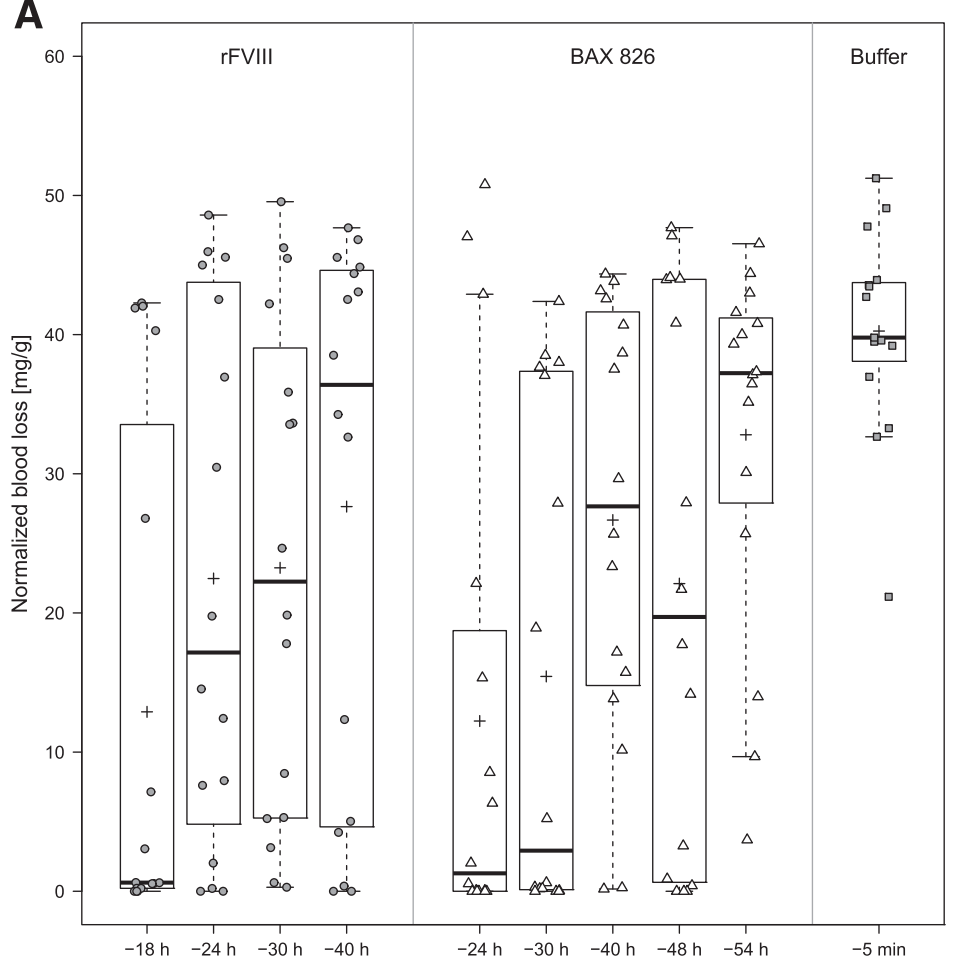

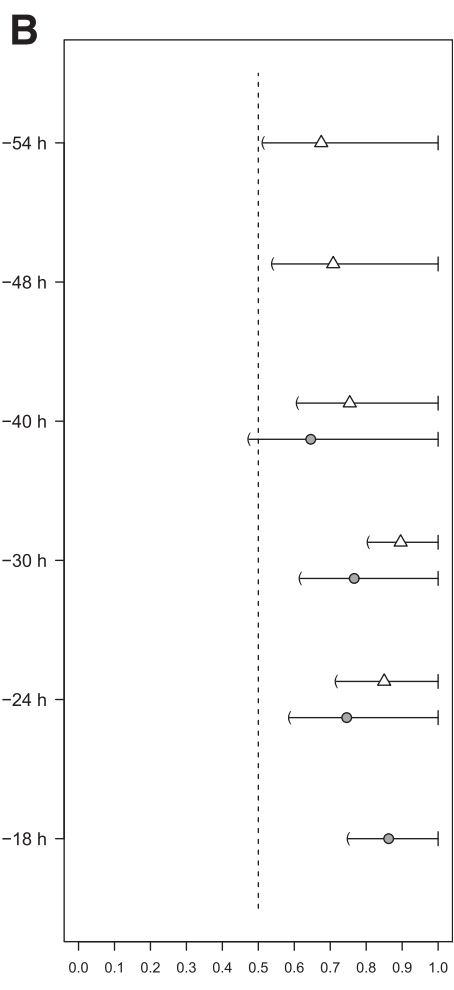

Relative effect

Fig. 5. Single-dose treatment with BAX 826 prolongs procoagulant activity vs. treatment with rFVIII in hemophilic FVIII KO mice. Buffer, unmodified rFVIII, or BAX 826 was administered intravenously at a dose of $200 \mathrm{IU} / \mathrm{kg}$ at the indicated time points before bleeds were started. (A) Body weight normalized blood loss over 60 minutes ( $n=15$ to 16/group) is displayed using boxplots. See the Supplemental Material for a description of the boxplots. (B) Relative effects and corresponding one-sided $95 \%$ confidence intervals (CIs) at the respective time points after treatment with rFVIII (gray circles) or BAX 826 (open triangles) are displayed. The relative effect provides a probability that a randomly selected animal treated with rFVIII or BAX 826 has a lower normalized blood loss than a randomly selected animal treated with buffer. The relative effect is 0.5 if both groups are stochastically equal. A onesided $95 \%$ CI for the relative effect not containing the value 0.5 , indicated by the vertical dashed line, is equivalent to rejecting the null hypothesis against the two-sided alternative of a lower normalized blood loss than with buffer at the $5 \%$ level of statistical significance.

$44.5 \%$ and $16.7 \%$, respectively. All animals treated with the activated prothrombin complex concentrate FEIBA showed evidence of thrombi formation (range 2-4; mean 3.50) with the majority at the highest possible score (4), confirming the validity of the model.

Toxicology Studies in Rats and Cynomolgus Monkeys. Intravenous administration of BAX 826 once every 5 days for 31 days in rats $(80,350$, or $800 \mathrm{U} / \mathrm{kg})$ and cynomolgus monkeys $(80,350$, or $600 \mathrm{U} / \mathrm{kg})$ was well tolerated. The no observed adverse effect levels were set at the highest dose levels in each species as detailed in the Supplemental Material. Repeated dosing of human BAX 826 protein to rats and cynomolgus monkeys was associated with development of anti-rFVIII/PSArFVIII antibodies in most animals.

\section{Discussion}

Available FVIII-based treatment options for hemophilia are being further developed to enhance aspects of their biology, most notably their half-life, functional activity, and immunogenicity (Laffan, 2016). Protein modifications with PSA have been proposed to maintain the structural integrity and activity of therapeutic proteins (Gregoriadis et al., 1993, 2005), while the degree of PSAylation can influence their immunologic and PK profiles (Fernandes and Gregoriadis, 2001; Constantinou et al., 2008). In accordance, the procoagulant potential of PSArFVIII was essentially maintained as demonstrated by normalization of an artificially prolonged activated partial thromboplastin time in vitro; however, binding to LRP1 and VWF was diminished and correlated inversely with degree of PSAylation.

PSArFVIII formulations also showed striking improvements in circulation time and exposures (mean ratio estimates up to 3-fold), although there was no clear tendency that increasing degrees of PSAylation further improved PSArFVIII PK behavior. While the procoagulative potential of PSArFVIII in the acute tail-bleeding assay did not differ from that for rFVIII, analysis of all available data suggested that moderate PSAylation approximating $10 \mathrm{~mol} / \mathrm{mol}$ is necessary for optimal pharmacologic activity and sufficient to prolong circulation time.

To address putative effects on immunogenicity, we used hemophilic mouse models representing either 1) relative immunotolerance to human rFVIII therapy or 2) an increased genetic risk of an immune response to rFVIII in humans (van Helden et al., 2011; Steinitz et al., 2012). The incidence of animals that tested positive for anti-rFVIII/PSArFVIII antibodies was numerically higher in rFVIII-treated groups than in PSArFVIII-treated groups in both models. However, the titers appeared similar and there were no further meaningful reductions in incidence with a higher degree of PSAylation (i.e., $13.3 \mathrm{~mol} / \mathrm{mol}$ ). These in vivo data are congruent with a previous report where one or two injections of unmodified insulin generated an immune response in mice, whereas four injections of PSA-insulin were needed to elicit a modest 

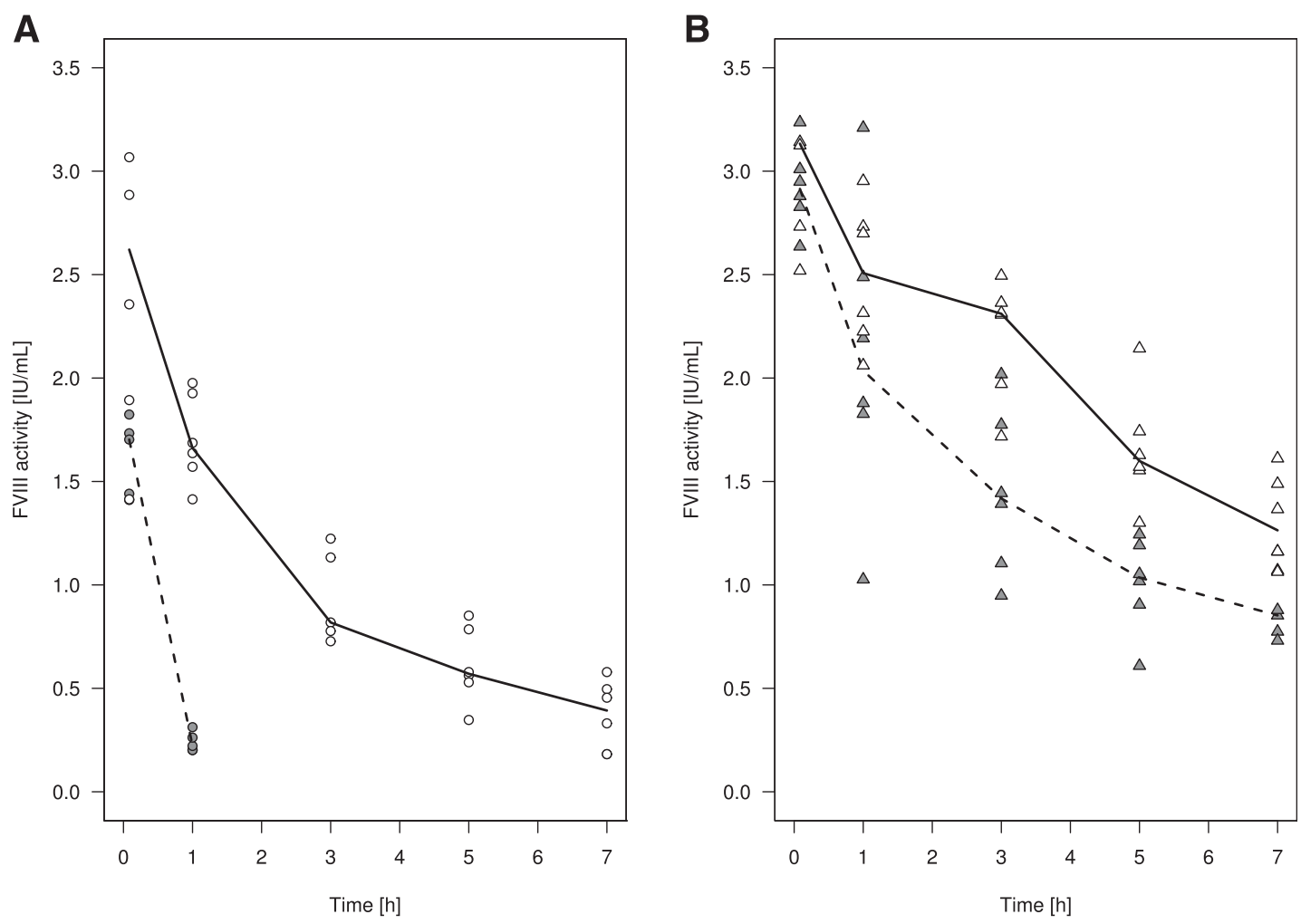

Fig. 6. Prolongation of BAX 826 circulation time is largely independent of circulating VWF in FVIII/VWF double-KO mice. Unmodified rFVIII (A) or BAX 826 (B) was administered at a dose of $200 \mathrm{IU} / \mathrm{kg}$ without and with $3000 \mathrm{U} / \mathrm{kg}$ of rVWF, and blood was sampled at the time points indicated. Individual FVIII activity is shown as gray circles and triangles (without VWF) or white circles and triangles (with VWF). Median values are shown as dashed lines (without VWF) or solid lines (with VWF). PK data were assessed using a serial sampling design, where only one sample is taken per animal at one of the time points investigated ( $n=6 /$ time point/group). The PK profiles of rVWF (data not shown) were similar when administered in combination with either rFVIII or BAX 826 as indicated by the respective median for $C_{\max }(35.83$ and $38.62 \mathrm{U} / \mathrm{ml})$, terminal half-life (6.3 and 6.1 hours), as well as area under the curve from time 0 to the last time point (148.1 and $149.8 \mathrm{U} / \mathrm{ml} * \mathrm{~h}$ ).

response (Jain et al., 2003; Gregoriadis et al., 2005). Adding PSA to human FVIII does not appear to negatively affect the immunogenicity profile of FVIII and could potentially affect its immunogenicity profile favorably; however, no final proof of decreased immunogenic potential can be deduced from animal studies. BAX 826 did not increase activation of the human innate immune system or of complement pathways (C5a) compared with rFVIII in vitro, although potential development of anti-PSA antibodies was noted after repeated administration of BAX 826 to rats and monkeys (manuscript in preparation).
In summary, in vitro data suggested that increasing degrees of FVIII PSAylation correlated with reduced interactions with LRP1 and VWF and a holistic assessment was used to narrow a preferable PSAylation degree in vivo. PSAylation degrees $\geq 10.4 \mathrm{~mol} / \mathrm{mol}$ provided significant half-life extension ratios versus rFVIII, whereas higher PSAylation degrees $\geq 13.3 \mathrm{~mol} / \mathrm{mol}$ resulted in more variable efficacies at intermediate dose levels and were without additional benefit when assessing immunogenicity risks in mice. These combined attributes suggested a PSAylation degree of about $10 \mathrm{~mol} / \mathrm{mol}$ as a preferable target.

TABLE 4

Summary of PK parameters after single-dose intravenous administration of $200 \mathrm{U} / \mathrm{kg}$ BAX 826 or rFVIII to FVIII/VWF double-KO mice, without or with rVWF coadministration

Values in parentheses refer to two-sided $95 \%$ confidence intervals; $n=6 /$ group/time point.

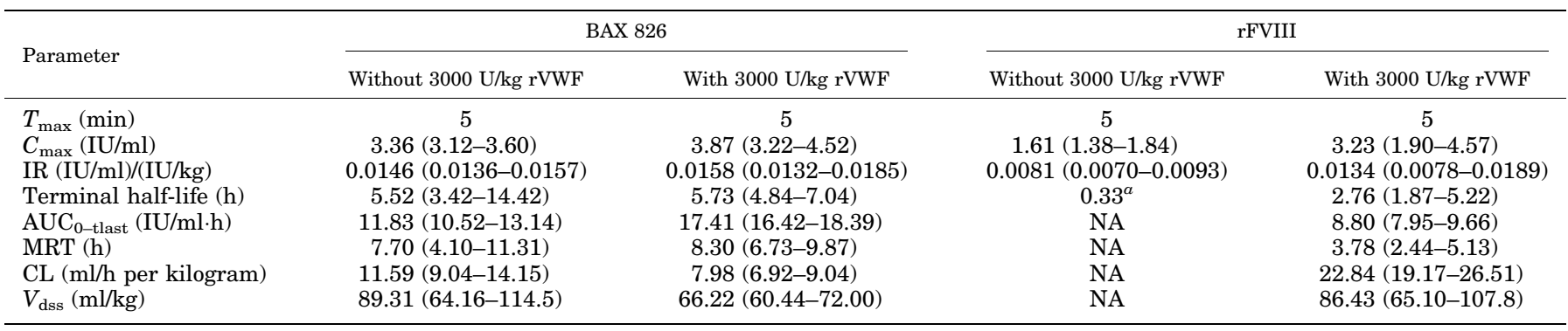

$\mathrm{AUC}_{0-\text { tlast }}$, area under the curve from time 0 to the last time point; CL, clearance; $C_{\max }$, peak plasma concentration; IR, incremental recovery; NA, not available; $T_{\text {max }}$, time at $C_{\mathrm{max}} ; V_{\mathrm{dss}}$, volume of distribution at steady state.

${ }^{a}$ Linear regression on $\log _{\mathrm{e}}$-transformed individual concentrations resulted in a terminal half-life of $0.3307 \mathrm{~h}$ (95\% confidence interval: $0.2955-0.3755$ ). 
TABLE 5

Summary of PK parameters after single-dose intravenous administration of BAX 826 or rFVIII (350 U/kg) to cynomolgus monkeys evaluated with PSAFVIII modification-dependent activity assay or chromogenic assay as described in Materials and Methods

Except for $T_{\max }$, all values in parentheses refer to two-sided $95 \%$ confidence intervals; $n=6$ /group.

\begin{tabular}{|c|c|c|c|}
\hline \multirow{2}{*}{ Parameter } & \multicolumn{2}{|c|}{ BAX 826} & rFVIII \\
\hline & \multirow{2}{*}{ Assay Format: MDAA } & \multicolumn{2}{|c|}{ Assay Format: Chromogenic } \\
\hline$T_{\max }[$ median minutes (range)] & & $5(5-30)$ & $5(5-5)$ \\
\hline Terminal half-life (h) & $13.5(11.7-15.5)$ & $18.5(13.2-26.0)$ & $8.0(4.7-13.5)$ \\
\hline $\operatorname{AUC}_{0-\text { tlast }}(\mathrm{IU} / \mathrm{ml} \cdot \mathrm{h})$ & $127(91-178)$ & $189(146-245)$ & $39.6(28.0-55.9)$ \\
\hline $\operatorname{AUC}_{0-\infty}(\mathrm{IU} / \mathrm{ml} \cdot \mathrm{h})$ & $129(93-179)$ & $206(160-266)$ & $48.2(33.3-69.7)$ \\
\hline
\end{tabular}

$\mathrm{AUC}_{0-\text { tlast }}$, area under the curve from time 0 to the last time point; $\mathrm{AUC}_{0-\infty}$, area under the curve from time 0 to infinity; CL, clearance; $C_{\text {max }}$, peak plasma concentration IR, incremental recovery; MDAA, modification-dependent activity assay; $T_{\max }$, time at $C_{\max } ; V_{\mathrm{dss}}$, volume of distribution at steady state.

Restrained immunogenicity potential of novel FVIII products might be beneficial in treating hemophilia; however, systemic clearance of FVIII is largely determined by the plasma level of VWF (Björkman and Berntorp, 2001; Pipe et al., 2016). While binding of PSArFVIII to VWF is diminished in vitro, the circulation time of BAX 826 in FVIII KO mice (VWF-competent mice) was clearly prolonged. We further interrogated this mechanistic relationship in vivo using VWF-deficient mice in a reconstitution experiment with human rVWF. Compared with BAX 826 MRT in wild-type mice (9.06 hours), the circulation time remained relatively prolonged (7.7 hours) in VWF-deficient animals. Coadministration of human rVWF had a nonsignificant effect on BAX 826 MRT (8.3 hours), whereas the circulation time of unmodified rFVIII ( 0.33 hours) was substantially restored by reconstitution with VWF. This observation is consistent with in vitro binding data, indicating markedly reduced PSArFVIII/VWF interaction. Previous studies with PEGylated full-length or
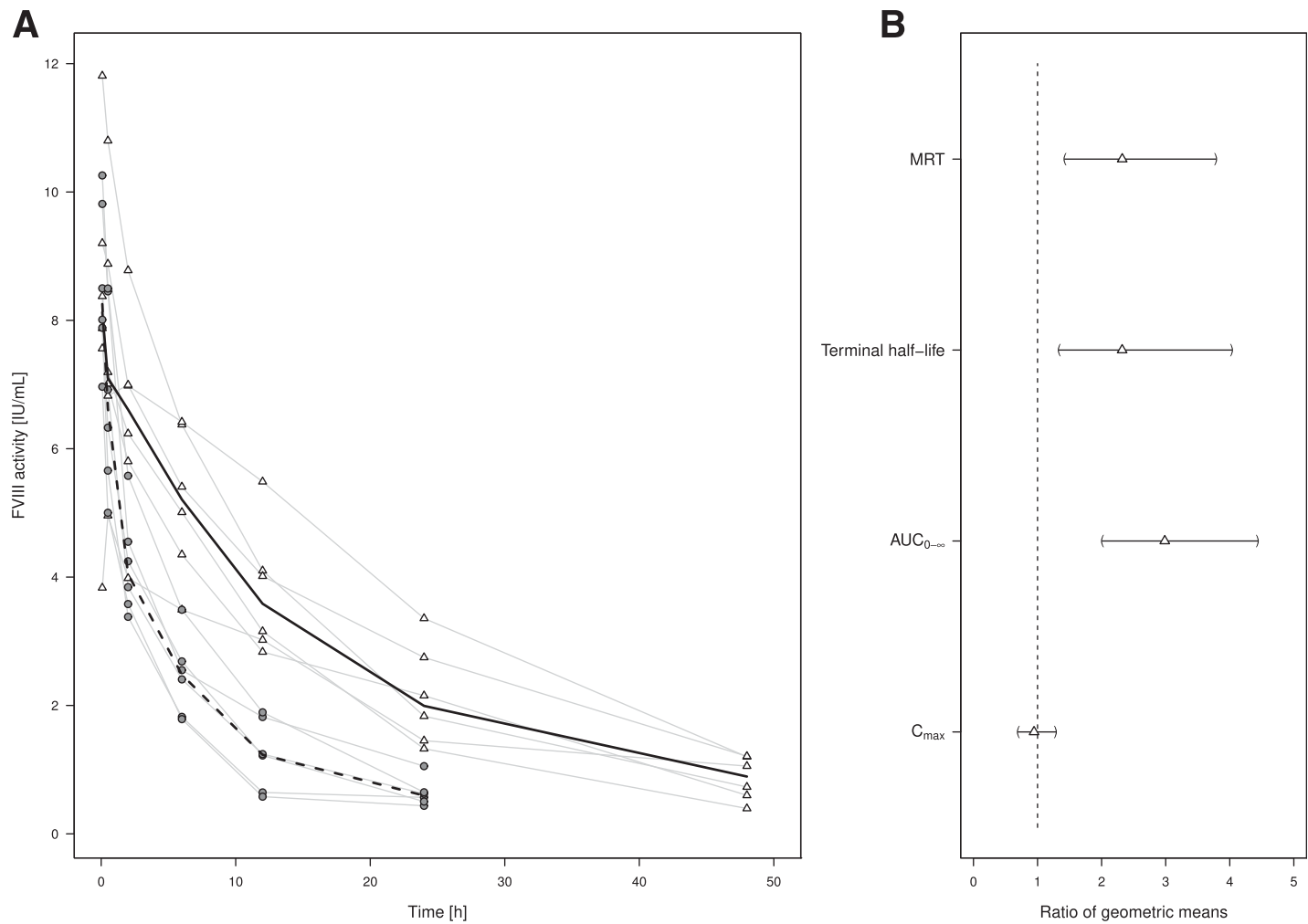

Fig. 7. Comparative PK analyses in plasma of cynomolgus monkey reveals prolonged circulation of BAX 826 vs. rFVIII. Unmodified rFVIII or BAX 826 was administered intravenously ( $n=6 /$ group) at a dose of $350 \mathrm{IU} / \mathrm{kg}$ and blood was sampled at the time points indicated. FVIII activity was baseline corrected to account for endogenous monkey FVIII activity. (A) Individual FVIII activity is shown as gray circles (rFVIII) or white triangles (BAX 826) with thin lines connecting measurements over time per animal. Median values are shown as dashed lines (rFVIII) or solid lines (BAX 826). (B) Shown are ratios of geometric mean values (BAX 826/rFVIII) and corresponding two-sided 95\% confidence intervals (CIs) of the PK parameter maximum concentrations $\left(C_{\max }\right)$, area under the curve from time 0 to infinity $\left(\mathrm{AUC}_{0-\infty}\right)$, terminal half-life, and MRT. A two-sided $95 \% \mathrm{CI}$ for the ratio not containing the value of 1 , indicated by the vertical dashed line, is equivalent to rejecting the null hypothesis of no difference against the two-sided alternative at the $5 \%$ level of statistical significance. 
B-domain-deleted rFVIII have shown relatively unchanged interactions with VWF (Turecek et al., 2012; Tang et al., 2013). The data suggest a differentiated mechanism for the EHL of PSArFVIII that is largely, although not entirely, independent of interaction with VWF in vivo, whereas they do not exclude PSArFVIII/VWF interactions in vivo in the pharmacologic control of hemostasis. However, by extension these results might infer a relatively maintained EHL attribute for PSArFVIII in human pathologies in which circulating VWF is rate limiting (Favaloro, 2016). In aggregate, the current data suggest that PSArFVIII EHL comprises two possibly intertwined mechanisms: reduced binding to scavenger receptors (i.e., LRP1) and a largely VWF interaction-independent circulation time. The current data do not exclude that additional physiologic mechanisms and FVIII interactions (Pipe et al., 2016) might potentially be affected by PSAylation of rFVIII.

It has been recognized that the time-consuming nature of a prophylaxis regimen that typically involves two to four infusions per week is the greatest treatment-related barrier to adherence in children and adults receiving prophylaxis for hemophilia (Thornburg and Duncan, 2017). To support the effective translation of improved PK behavior into a period of extended pharmacodynamic activity, we have applied an orthogonal approach demonstrating prophylactic reductions in blood loss over an extended period of effectiveness as well as prolonged procoagulant (thrombotic) activity in hemophilic FVIII-deficient mice. The clinical relevance of these findings can be inferred from a previous study in the same mouse model that demonstrated prolonged prophylactic efficacy for a clinical EHL FVIII therapeutic (PEG-rFVIII) over a similar period (Turecek et al., 2012).

A recent report suggests that EHL rFVIII products should have a minimum half-life extension ratio of 1.3 to allow a reduction in dosing frequency from 3 to 2 times/week compared with standard rFVIII products while maintaining the same minimum FVIII trough level (Hermans et al., 2018). Comparative analyses of key PK parameters in nonhuman primates clearly demonstrated that treatment with BAX 826 or rFVIII shows equivalent $C_{\max }$ values yet produces significantly increased area under the curve and circulation time, as indicated by a 3 -fold reduction in clearance and greater than 2-fold prolongations of MRT and half-life.

Considering the availability of safe and effective FVIII replacement therapies (Cafuir and Kempton, 2017), the safety profile of novel modifications of rFVIII, such as BAX 826 , needs to be scrutinized. As a first step, the evaluation of BAX 826 thrombogenicity potential during venous stasis did not show differences between BAX 826 and rFVIII. BAX 826 was also well tolerated in rats and monkeys in repeat-dose toxicity studies up to 5 weeks, with no mortalities, clinical signs, or pathology directly attributable to BAX 826 at exposure levels up to 14.9 -fold above those tested in mice. However, both rat and monkey species showed development of binding and neutralizing antibodies against BAX 826 and rFVIII, which is an expected immune response after repeated application of a heterologous protein and not predictive of the human situation. The presence of neutralizing antibodies correlated with the decrease in exposure and prolongation of activated partial thrombin time after repeated application of BAX 826, and all sequelae were attributed to antibodies crossreacting with monkey FVIII protein.
The rationale of the presented approach is based on unmodified rFVIII with PSA conjugation predominantly within the FVIII B-domain, a domain not essential and not present in activated FVIII protein. Site-directed FVIII PSAylation of particular glycans or substitution of FVIII residues to allow for site-directed protein chemistries would present alternative conjugation strategies. While there are advantages to these approaches there are also caveats that would need to be considered, such as a potential increase in immunogenic risks. Nevertheless, site-specific polysialylation of modified proteins is feasible (Constantinou et al., 2009) and site-specific PEGylated FVIII variants are in clinical development (Tiede, 2015).

In summary, comprehensive preclinical evaluation of PSArFVIII defined a preferable degree of rFVIII polysialylation, resulting in identification of BAX 826. BAX 826 demonstrated a favorable nonclinical safety profile and all characteristics of an EHL rFVIII product compared with unmodified rFVIII. These features recommended BAX 826 for further clinical evaluation as a potential EHL treatment option for hemophilia.

\section{Acknowledgments}

The authors thank Dr. Jürgen Siekmann for technical support in for technical expertise in conducting in vivo studies.

\section{Authorship Contributions}

Conducted experiments: Dockal, Ehrlich, Gritsch, Höbarth, Horling, Kopic, Leidenmühler, Rottensteiner, Ruthsatz, Schrenk, Schuster, Weber.

Performed data analysis: Glantschnig, Benamara, Bauer, Dockal, Gritsch, Horling, Leidenmühler, Reipert, Rottensteiner, Schrenk, Turecek, Weber, Wolfsegger, Scheiflinger, Höllriegl.

Wrote or contributed to the writing of the manuscript: Glantschnig, Bauer, Benamara, Scheiflinger, Schrenk, Höllriegl.

\section{References}

Balkaransingh P and Young G (2018) Novel therapies and current clinical progress in hemophilia A. Ther Adv Hematol 9:49-61.

Baumgartner B, Jaki T, Wolfsegger MJ, Eder B, Schiviz A, Schwarz HP, and Muchitsch EM (2010) Optimization, refinement and reduction of murine in vivo experiments to assess therapeutic approaches for haemophilia A. Lab Anim 44:211-217.

Bi L, Lawler AM, Antonarakis SE, High KA, Gearhart JD, and Kazazian HH Jr (1995) Targeted disruption of the mouse factor VIII gene produces a model of haemophilia A. Nat Genet 10:119-121.

Björkman S and Berntorp E (2001) Pharmacokinetics of coagulation factors: clinical relevance for patients with haemophilia. Clin Pharmacokinet 40:815-832.

Cafuir LA and Kempton CL (2017) Current and emerging factor VIII replacement products for hemophilia A. Ther Adv Hematol 8:303-313.

Constantinou A, Epenetos AA, Hreczuk-Hirst D, Jain S, and Deonarain MP (2008) Modulation of antibody pharmacokinetics by chemical polysialylation. Bioconjug Chem 19:643-650.

Constantinou A, Epenetos AA, Hreczuk-Hirst D, Jain S, Wright M, Chester KA and Deonarain MP (2009) Site-specific polysialylation of an antitumor single-chain Fv fragment. Bioconjug Chem 20:924-931.

Coyle TE, Reding MT, Lin JC, Michaels LA, Shah A, and Powell J (2014) Phase I study of BAY 94-9027, a PEGylated B-domain-deleted recombinant factor VIII with an extended half-life, in subjects with hemophilia A. J Thromb Haemost 12:488-496.

Dhillon S (2012) Octocog alfa, antihaemophilic factor (recombinant), plasma/albumin free method (Advate®): a review of its use in the management of patients with haemophilia A. Drugs 72:987-1007.

Dumont JA, Liu T, Low SC, Zhang X, Kamphaus G, Sakorafas P, Fraley C, Drager D, Reidy T, McCue J, et al. (2012) Prolonged activity of a recombinant factor VIII-Fc fusion protein in hemophilia A mice and dogs. Blood 119:3024-3030.

Favaloro EJ (2016) Towards personalised therapy for von Willebrand disease: a future role for recombinant products. Blood Transfus 14:262-276.

Fernandes AI and Gregoriadis G (2001) The effect of polysialylation on the immunogenicity and antigenicity of asparaginase: implication in its pharmacokinetics. Int $J$ Pharm 217:215-224.

Gregoriadis G, Fernandes A, Mital M, and McCormack B (2000) Polysialic acids: potential in improving the stability and pharmacokinetics of proteins and other therapeutics. Cell Mol Life Sci 57:1964-1969. 
Gregoriadis G, Jain S, Papaioannou I, and Laing P (2005) Improving the therapeutic efficacy of peptides and proteins: a role for polysialic acids. Int $J$ Pharm 300: $125-130$.

Gregoriadis G, McCormack B, Wang Z, and Lifely R (1993) Polysialic acids: potential in drug delivery. FEBS Lett 315:271-276

Hermans C, Mahlangu J, Booth J, Schütz H, Santagostino E, Young G, Lee HY, Steinitz-Trost KN, Blanchette V, and Berntorp E (2018) Pharmacokinetic modelling and validation of the half-life extension needed to reduce the burden of infusions compared with standard factor VIII. Haemophilia 24:376-384.

Jain S, Hreczuk-Hirst DH, McCormack B, Mital M, Epenetos A, Laing P, and Gregoriadis G (2003) Polysialylated insulin: synthesis, characterization and biological activity in vivo. Biochim Biophys Acta 1622:42-49.

Konkle BA, Stasyshyn O, Chowdary P, Bevan DH, Mant T, Shima M, Engl W, Dyck-Jones J, Fuerlinger M, Patrone L, et al. (2015) Pegylated, full-length, recombinant factor VIII for prophylactic and on-demand treatment of severe hemophilia A. Blood 126:1078-1085.

Laffan M (2016) New products for the treatment of haemophilia. Br J Haematol 172: $23-31$.

Mahlangu J, Powell JS, Ragni MV, Chowdary P, Josephson NC, Pabinger I, Hanabusa H, Gupta N, Kulkarni R, Fogarty P, et al.; A-LONG Investigators (2014) Phase 3 study of recombinant factor VIII Fc fusion protein in severe hemophilia A. Blood 123:317-325.

Mahlangu J, Young G, Hermans C, Blanchette V, Berntorp E, and Santagostino E (2018) Defining extended half-life rFVIII-A critical review of the evidence. Haemophilia 24:348-358.

Peyvandi F, Garagiola I, and Seregni S (2013) Future of coagulation factor replacement therapy. J Thromb Haemost 11 (Suppl 1):84-98.

Pipe SW (2005) The promise and challenges of bioengineered recombinant clotting factors. J Thromb Haemost 3:1692-1701.

Pipe SW, Montgomery RR, Pratt KP, Lenting PJ, and Lillicrap D (2016) Life in the shadow of a dominant partner: the FVIII-VWF association and its clinical implications for hemophilia A. Blood 128:2007-2016.

Schiviz A, Magirr D, Leidenmühler P, Schuster M, Muchitsch EM, and Höllriegl W; Subcommittee on Animal Models of the Scientific and Standardization Committee of the International Society on Thrombosis and Hemostasis (2014) Influence of genetic background on bleeding phenotype in the tail-tip bleeding model and recommendations for standardization: communication from the SSC of the ISTH. $J$ Thromb Haemost 12:1940-1942.

Schrenk G, Podeu R, Ullmer R, Foettinger-Vacha A, Graninger M, Turecek PL, Dockal M, Mitterer A, and Scheiflinger F (2016) Structural and functional characterization of preclinical and clinical batches of BAX 826, a PSAylated full-length recombinant FVIII. Haemophilia 22 (Suppl 4):78.
Siekmann J, , Haider S, , Rottensteiner HP, and, and Turecek P (2014) inventors. Blood coagulation protein conjugates. U.S. patent 8,637,640 B2. Assignees: Baxter International Inc., Deerfield, IL (US); Baxter Healthcare SA, Glattpark (Opfikon) (CH). Date of Patent: Jan. 28, 2014

Steinitz KN, van Helden PM, Binder B, Wraith DC, Unterthurner S, Hermann C, Schuster M, Ahmad RU, Weiller M, Lubich C, et al. (2012) CD4 ${ }^{+}$T-cell epitopes associated with antibody responses after intravenously and subcutaneously applied human FVIII in humanized hemophilic E17 HLA-DRB1*1501 mice. Blood 119:4073-4082.

Tang L, Leong L, Sim D, Ho E, Gu JM, Schneider D, Feldman RI, Monteclaro F, Jiang H, and Murphy JE (2013) von Willebrand factor contributes to longer halflife of PEGylated factor VIII in vivo. Haemophilia 19:539-545.

Tiede A (2015) Half-life extended factor VIII for the treatment of hemophilia A. $J$ Thromb Haemost 13 (Suppl 1):S176-S179.

Tiede A, Brand B, Fischer R, Kavakli K, Lentz SR, Matsushita T, Rea C, Knobe K, and Viuff D (2013) Enhancing the pharmacokinetic properties of recombinant factor VIII: first-in-human trial of glycoPEGylated recombinant factor VIII in patients with hemophilia A. J Thromb Haemost 11:670-678.

Thornburg CD and Duncan NA (2017) Treatment adherence in hemophilia. Patient Prefer Adherence 11:1677-1686.

Toole JJ, Pittman DD, Orr EC, Murtha P, Wasley LC, and Kaufman RJ (1986) A large region (approximately equal to $95 \mathrm{kDa}$ ) of human factor VIII is dispensable for in vitro procoagulant activity. Proc Natl Acad Sci USA 83:5939-5942.

Turecek PL, Bossard MJ, Graninger M, Gritsch H, Höllriegl W, Kaliwoda M, Matthiessen P, Mitterer A, Muchitsch EM, Purtscher M, et al. (2012) BAX 855, a PEGylated rFVIII product with prolonged half-life. Development, functional and structural characterisation. Hamostaseologie 32 (Suppl 1):S29-S38. van Helden PM, Unterthurner S, Hermann C, Schuster M, Ahmad RU, Schiviz AN, Weiller M, Antoine G, Turecek PL, Muchitsch EM, et al. (2011) Maintenance and break of immune tolerance against human factor VIII in a new transgenic hemophilic mouse model. Blood 118:3698-3707.

Wessler S, Reimer SM, and Sheps MC (1959) Biologic assay of a thrombosis-inducing activity in human serum. $J$ Appl Physiol 14:943-946.

Zhang T, She Z, Huang Z, Li J, Luo X, and Deng Y (2014) Application of sialic acid/ polysialic acid in the drug delivery systems. Asian J Pharm Sci 9:75-81.

Address correspondence to: Werner Höllriegl, Drug Discovery Austria, Baxalta Innovations $\mathrm{GmbH}$, a Member of the Takeda Group of Companies, Donau City Strasse 7, Vienna A-1220, Austria. E-mail: werner.hoellriegl@ takeda.com 